\title{
Marco jurídico de las estaciones termales(*)
}

\author{
Francisco Javier Melgosa Arcos \\ Universidad de Salamanca
}

(*) Referencia bibliográfica: MELGOSA ARCOS, F. J. Marco jurídico de las estaciones termale", en Revista de la Sociedad Española de Hidrología Médica, núm. 1 de 2000. Págs. 13 a 27.

Una de las alternativas al turismo convencional es la que ofrecen las estaciones termales o balnearios, tanto por su carácter intrínseco de centro de salud como por las posibilidades que presentan los entornos en que se hallan enclavadas. En la mayoría de los países europeos las estaciones termales han sabido conjugar a la perfección esa doble actividad sanitaria/turística, enriqueciéndola con nuevas ofertas de ocio.

También forman parte de la oferta de turismo de salud los denominados "cuhoteles" que son establecimientos hoteleros que ofrecen las instalaciones y servicios profesionales necesarios para promover y mejorar la salud de sus clientes, como sucede, por ejemplo, con los Centros de Talasoterapia de la costa mediterránea.

Un estudio de las estaciones termales puede englobar múltiples aspectos: arqueológicos, medicinal, económico, social, histórico, lúdico, ... etc., pero en el presente estudio sólo se analizará la compleja y muchas veces, ambigua ordenación administrativa, pues como acertadamente señala DAVID BLANQUER ${ }^{1}$ la singularidad de los establecimientos termales conlleva una ordenación jurídica más compleja que la de otros establecimientos turísticos, al tener que iniciar, varios procedimientos administrativos. Como mínimo, uno para obtener la declaración de agua mineromedicinal o termal; otro para disponer de la concesión administrativa de aprovechamiento de dicho agua; en tercer lugar, una autorización de la Administración sanitaria; y por último, una autorización de la Administración Turística sobre las instalaciones alojativas.

Pero además, en estas tramitaciones, hay que tener en cuenta las nuevas regulaciones de las CCAA, surgidas como consecuencia de la distribución competencial operada por la Constitución de 1978, que afecta a las aguas minero-mecicinales, turismo, sanidad, etc.

\section{I.- DISTRIBUCIÓN DE COMPETENCIAS EN LA CONSTITUCIÓN ESPAÑOLA DE 1978 SOBRE AGUAS MINERALES Y TERMALES. LEGISLACIÓN DE LAS COMUNIDADES AUTÓNOMAS}

Las aguas minerales y termales, a pesar de su carácter subterráneo, reciben un tratamiento constitucional diferenciado. Así, atendiendo a la Constitución y a los Estatutos de Autonomía, la competencia sobre la materia es de cada CCAA sin perjuicio de las

${ }^{1}$ BLANQUER CRIADO, D. “Derecho del Turismo”. Tirant lo Blanch, Valencia, 1999. 
competencias estatales de carácter básico. No obstante, como señala SILVIA DEL SAZ ${ }^{2}$ “dada la remisión de la Ley de Aguas a la legislación específica para la regulación de las aguas minerales y termales, resulta necesario poner en relación el artículo 148.1.10 con el 149.1.25 que atribuye al Estado la competencia exclusiva para fijar la legislación básica del régimen minero y energético, de donde se deriva que las CCAA deberán ejercer la competencia exclusiva sobre aguas minerales y termales en el marco de la legislación básica estatal en materia de recursos mineros y energéticos”.

La normativa básica estatal se contiene en la Ley 22/1973, de 21 de julio, de Minas, en su nueva redacción operada por Decreto Legislativo 1303/1986, de 28 de junio, por el que se adecua al Ordenamiento de la Unión Europea; en el R.D. 2857/1978, de 25 de agosto, por el que se aprueba el Reglamento General para el Régimen de la Minería; en el R.D. 1164/1991, de 22 de julio, por el que se aprueba la Reglamentación técnico-sanitaria para la elaboración, circulación y comercio de aguas de bebida envasada; y en el R.D.L. 743/1928, de 25 de abril, por el que se aprueba el Estatuto sobre la explotación de manantiales de aguas mineromedicinales (en la parte no derogada por la Disposición Final quinta de la Ley de Minas, y que no entre en contradicción con otra legislación posterior).

Las competencias que atribuye el artículo 148.1.10 CE fueron asumidas por las CCAA en sus Estatutos de Autonomía ${ }^{3}$, y se hicieron efectivas a través de los Reales Decretos de Transferencias, por los que se traspasaban personal y servicios en materia de industria, energía y minas; entre los que se incluía, aguas minerales.

Sin embargo, hasta la fecha sólo cuatro CCAA han legislado al respecto: Cantabria, Castilla-La Mancha, Extremadura y Galicia.

a).- Cantabria:

- Ley 2/1988, de 26 de octubre, de Fomento, Ordenación y Aprovechamiento de los Balnearios y de las Aguas Minero-medicinales y/o Termales.

- $\quad$ Ley 8/1990, de 12 de abril, por la que se modifica el artículo 7 de la Ley 2/1988.

b).- Castilla-La Mancha:

- $\quad$ Ley 8/1990, de 28 de diciembre, de Aguas Minerales y Termales.

- Orden de 30 de abril de 1991, sobre autorizaciones administrativas de establecimientos balnearios.

- Decreto 4/1995, de 31 de enero de 1995, por el que se regula el Reglamento para la ejecución de la Ley 8/1990.

c).- Extremadura:

- Ley 6/1994, de 24 de noviembre, de Balnearios y de Aguas minero-medicinales y/o Termales.

d).- Galicia:

²DEL SAZ CORDERO, S. “Aguas subterráneas, aguas públicas”. Marcial Pons, Madrid, 1990.

${ }^{3}$ Andalucía: Ley Orgánica 6/1981, de 30 de diciembre; Baleares: Ley Orgánica 2/1983, de 25 de febrero; Canarias: Ley Orgánica 10/1982, de 10 de agosto; Castilla y León: Ley Orgánica 4/1983, de 25 de febrero; Cataluña: Ley Orgánica 4/1979, de 18 de diciembre; Comunidad de Madrid: Ley Orgánica 3/1983, de 25 de febrero; Comunidad Valenciana: Ley Orgánica 5/1982, de 1 de julio; etc. 
- Ley 5/1995, de 7 de junio, de Regulación de las Aguas Minerales, Termales y de Manantial y de los Establecimientos Balnearios.

- Decreto 402/1996, de 31 de octubre, por el que se regula el Reglamento de aprovechamiento de aguas minero-medicinales, termales y de los establecimientos balnearios.

También se da la circunstancia de que estos Reglamentos han sido recurridos ante la jurisdicción contenciosa-administrativa por la Asociación Española de Estaciones Termales (ANET), que ya ha visto estimadas sus pretensiones contra el Decreto 28/1990, de 30 de mayo, por el que se aprobó el Reglamento de Fomento, Ordenación y Aprovechamiento de los Balnearios y de las Aguas minero-medicinales y Termales de Cantabria, al ser declarado nulo en la STS de 26 de noviembre de 1998, por haber omitido el dictamen del Consejo de Estado $^{4}$. Esta oposición de la propiedad balnearia ha frenado en parte la iniciativa legislativa de otras CCAA, que quedará condicionada por los pronunciamientos del Tribunal Supremo sobre los otros recursos planteados.

Coincido con CARO-PATÓN ${ }^{5}$ en que las normas aprobadas por las CCAA -al igual que la norma estatal- resultan excesivamente complejas y ambiguas, sin favorecer la explotación económica de las aguas minerales y de manantial.

\section{II.- EL PROBLEMA DE LA LEGISLACIÓN APLICABLE. NATURALEZA PÚBLICA O PRIVADA}

La Ley 29/1985, de 2 de agosto, de Aguas (modificada por Ley 46/1999, de 13 de diciembre), en su artículo 1.4 establece que "Las aguas minerales y termales se regularán por su legislación específica”, es decir, por la Ley 22/1973, de 21 de julio, de Minas.

Esta exclusión de las aguas minerales y termales de la LAg. fue criticada en la fase de tramitación parlamentaria. Una buena parte de la doctrina ${ }^{6}$ entiende que no existen razones científicas ni técnicas que justifiquen la regulación de las aguas minerales y termales en la legislación de minas, en lugar de la legislación de aguas. GUAITA ha señalado que las aguas minerales de la sección B) de la Ley de Minas, a diferencia del resto de las secciones de la LM, no son minerales en sentido vulgar, sino que tienen una naturaleza físico-química híbrida (aguas no comunes sino minerales; recursos geológicos pero no yacimientos minerales) ${ }^{7}$. Además, esta exclusión choca contra uno de los principios inspiradores de la Ley de Aguas, como es el de la unidad del ciclo hidrológico.

\footnotetext{
${ }^{4}$ La Sala reitera que el dictamen del Consejo de Estado cuando se trata de Reglamentos Autonómicos es preceptivo y señala que para que una CCAA pueda sustituir de forma voluntaria, en la elaboración de un Reglamento que sea desarrollo de una Ley Autónoma, el preceptivo dictamen del Consejo de Estado, es preceptivo que previamente haya hecho uso de sus facultades de autoorganización y creado un órgano consultivo propio con las mismas características y con idénticas facultades o semejantes funciones a los del Consejo de Estado.
}

${ }^{5}$ CARO-PATÓN CARMONA, I. “Usos turísticos de los cursos de agua”. (III Jornadas de Derecho y Turismo). Fundación Cultural Santa Teresa, Ávila, 1999.

${ }^{6}$ M. R. LLAMAS y E. CUSTODIO (“El proyecto de Ley de Aguas ...”, cit. Pp. 10 y ss.). ARIÑO (“El proyecto de Ley de aguas ...”, cit., pp. 103 y ss.).

${ }^{7}$ GUAITA “Derecho Administrativo. Aguas, montes, minas”. Cívitas, Madrid, 1982. 
Otra de las discusiones doctrinales se centra sobre la naturaleza pública o privada de las aguas minerales. Para una parte de la doctrina está claro que se trata de unas aguas de propiedad pública. Así, GONZÁLEZ PÉREZ ${ }^{8}$ señala, que como la Ley de Aguas considera de dominio público estatal todas las aguas continentales superficiales y las subterráneas renovables (art.1.2), se ha superado la posible contradicción y no ofrece duda que las aguas minerales y termales, como las demás, son de dominio público. Igual postura mantienen, entre otros, MENÉNDEZ REXACH ${ }^{9}$ y DE LA CUÉTARA ${ }^{10}$.

Esta postura quedaría reforzada por la Ley 8/1990, de 28 de diciembre, de aguas minerales y termales de Castilla-La Mancha, al establecer en su artículo 1.1. que: Las aguas minerales y termales constituyen un recurso declarado de utilidad pública, que forma parte del dominio público del Estado en los términos que establecen las legislaciones básicas estatales de agua y de minas. Las otras legislaciones autonómicas no entran en estas consideraciones.

Por otro lado, existen opiniones doctrinales que defienden la naturaleza privada de las aguas minerales y termales. Para SEBASTIÁN MARTÍN-RETORTILLO, la vigente LAg. no ha operado alteración alguna en la titularidad de las aguas minerales y termales. Sigue viva su posible consideración, en algunos casos, como aguas privadas. Y razona su tesis argumentando que la remisión que la LM hace, lo es al Código Civil y a la legislación especial; y los artículos que la vigente L.Ag. deroga expresamente del Código, lo son en cuanto se opongan a ella (Disposición Derogatoria $1^{a}$ ). Y tal oposición no se da, ni puede darse en el caso que consideramos, ya que, por lo que la misma Ley establece, nada de ella es referible a las aguas minerales y termales. Habrá que entender, pues, que queda vigente en este punto lo establecido en el Código Civil ${ }^{11}$. Estos planteamientos son defendidos también por la Asociación Española de Estaciones Termales.

La Jurisprudencia adoptó una solución intermedia, al distinguir entre aguas minerales e industriales, aplicando a estas últimas las Ley de Minas (lo que conlleva naturaleza demanial) mientras que para las minerales mantiene el criterio de accesión determinado en el artículo 16 de la Ley de Aguas (SSTS de 22 de diciembre de 1970, 14 de junio de 1972, 23 de enero de 1975 y 17 de enero de 1977) ${ }^{12}$.

En cualquier caso, con independencia de cómo se resuelva este problema de la titularidad, de aplicarse la vigente Ley de Aguas, entiendo que los derechos adquiridos estarían salvaguardados por las Disposiciones Transitorias Primera ${ }^{13}$ y Segunda ${ }^{14}$.

\footnotetext{
${ }^{8}$ GONZÁLEZ PÉREZ, J. “Comentarios a la Ley de Aguas”. Cívitas, Madrid, 1987.

${ }^{9}$ MENÉNDEZ REXACH, A. “El Derecho de aguas en España”, MOPU, Madrid, 1986.

${ }^{10}$ DE LA CUÉTARA, J.M. “El nuevo régimen de las aguas subterráneas en España”. Tecnos, Madrid, 1989.

${ }^{11}$ MARTÍN-RETORTILLO, S. “Derecho de Aguas”. Cívitas, Madrid, 1997.

${ }^{12}$ Vid. VILLAR EZCURRA, J.L. "Régimen jurídico de las aguas minero-medicinales”. Montecorvo, Madrid, 1980.

13“"1.- Quienes, conforme a la normativa que se deroga, fueran titulares de aprovechamientos de aguas públicas en virtud de concesión administrativa o prescripción acreditada, así como de autorizaciones de ocupación o utilización del dominio público estatal, seguirán disfrutando de sus derechos, de acuerdo con el contenido de
} 
No obstante, estas Disposiciones deben ser interpretadas a la luz de los pronunciamientos del TC en Sentencia de 29 de noviembre de $1988^{15}$ (Ponente: Jesús Leguina Villa) sobre distintos recursos de inconstitucionalidad contra la Ley 29/1985, de Aguas, que entre otras cosas, rechaza la acusación de vulneración del principio de irretroactividad con la demanialización “ope legis” de las aguas continentales, así como la acusación de vulnerar las garantías del derecho de propiedad privada y de los derechos patrimoniales contemplados en el artículo 33 CE.

\section{III.- CLASES DE AGUAS MINERALES Y TERMALES. LA TALASOTERAPIA}

a.- Clasificaciónes legales.- A tenor de los artículos 23, de la Ley 22/1973, de 21 de julio, de Minas (modificada por Ley 54/1980, de 5 de noviembre) y 5, del Real Decreto 2857/1978, de 25 de agosto, por el que se aprueba el Reglamento General para el Régimen de la Minería, las aguas minerales se clasifican en tres categorías:

a).- Minero-medicinales: Las alumbradas natural o artificialmente, que por sus características y cualidades sean declaradas de utilidad pública.

b).- Minero-Industriales: Son las que permiten el aprovechamiento racional de las sustancias que contengan, entendiéndose incluidas dentro de este grupo las aguas tomadas del mar a estos efectos.

c).- Aguas termales: Son aquellas cuya temperatura de surgencia sea superior al menos en cuatro grados centígrados a la media anual del lugar donde alumbren, siempre que, caso de destinarse a usos industriales, la producción calorífica máxima sea inferior a quinientas termias por hora.

sus títulos administrativos y lo que la propia ley establece, durante un plazo máximo de setenta y cinco años a partir de la entrada en vigor de la misma, de no fijarse en su título otro menor.

2.- No podrán legalizarse, mediante inscripción en el Registro de Aguas, aquellos aprovechamientos de aguas definidas como públicas según la normativa anterior, si sus titulares acreditasen por acta de notoriedad, de conformidad con los requisitos de la legislación notarial e hipotecaria y en el plazo de tres años, contados a partir de la entrada en vigor de la presente ley, el derecho a la utilización del recursos en los mismos términos en ue se hubiera venido disfrutando el aprovechamiento durante veinte años.

Las actas de notoriedad, que se trasmiten durante el citado período de tres años gozarán de la exención total en el pago del ITPAJD, así como los de cualquier tasa, cano y arbitrio que en su caso hubieran de abonar. El derecho a la utilización del recurso se prolongará por el plazo de setenta y cinco años, contados desde la entrada en vigor de esta ley, sin perjuicio de que la Administración ajuste el caudal del aprovechamiento a las necesidades reales.

3.- Los actuales titulares de aprovechamientos de aguas, por cualquier otro concepto distinto de los anteriores, conservarán el derecho a la utilización del recurso de acuerdo con lo que se establece en las disposiciones siguientes".

${ }^{14}$ En el plazo de tres años, a partir de la entrada en vigor de la presente Ley, los titulares de algún derecho conforme a la legislación que se deroga, sobre aguas privadas procedentes de manantiales que vinieran utilizándose en todo o en parte, podrán acreditar el mismo, así como el régimen de utilización del recurso, ante el Organismo de cuenca, para su inclusión en el Registro de Aguas como aprovechamiento temporal de aguas privadas. Dicho régimen será respetado por un plazo máximo de cincuenta años. Quienes al término de dicho plazo, se encontraran utilizando los caudales, en virtud de título legítimo, tendrán derecho preferente para la obtención de la correspondiente concesión administrativa, de conformidad con lo previsto en la presente Ley...

${ }^{15}$ Vid. Fundamentos Jurídicos sexto, octavo, noveno y undécimo. 
Esta clasificación no ha sido seguida al pie de la letra por las CCAA que han legislado al efecto, con lo que pueden estar invadiendo una competencia estatal. Por ejemplo, Cantabria y Extremadura no contemplan la categoría de "minero-industrial”, mientras que Castilla-La Mancha y Galicia coinciden al establecer cinco idénticas categorías; sirva como muestra lo establecido al respecto por el Decreto 4/1995, por el que se establece el Reglamento para la ejecución de la Ley 8/1990, de 28 de diciembre, de aguas minerales y termales de Castilla-La Mancha:

a) Aguas minero-medicinales: Son aguas superficiales y subterráneas alumbradas natural o artificialmente que por su composición y, en su caso, por su temperatura, poseen propiedades terapéuticas susceptibles de ser utilizadas en establecimientos balnearios emplazados en el área de emergencia.

b) Aguas minerales-naturales: Son aguas subterráneas alumbradas natural o artificialmente, cuyo contenido en minerales, oligoelementos y otros componentes, así como por su pureza bacteriológica, producen en el organismo efectos favorables, complementarios de las funciones fisiológicas, sin poseer necesariamente propiedades terapéuticas.

c) Aguas de manantial: Son aguas subterráneas cuyo contenido en minerales, oligoelementos y otros componentes, cumplen las normas de potabilidad vigentes y que por su pureza bacteriológica natural son susceptibles de ser utilizadas como aguas de bebida envasadas.

d) Aguas minero-industriales: Son aguas superficiales o subterráneas cuyo elevado contenido en determinados elementos o sustancias minerales permiten un aprovechamiento industrial para la obtención de los mismos.

e) Aguas termales: Son aguas subterráneas cuya temperatura de surgencia sea superior al menos en cuatro grados centígrados a la media anual del lugar donde alumbren, siempre que, caso de destinarse a usos industriales, la producción calorífica máxima sea inferior a quinientas termias por hora.

Las anteriores clasificaciones legales se completarían con la establecida en el R.D. 1164/1991, de 22 de julio, por el que se aprueba la Reglamentación técnico-sanitaria para la elaboración, circulación y comercio de aguas bebidas envasadas (Modificado por R.D. 781/1998, de 30 de abril), aprobado para adecuarse a la Directiva 80/777/CEE del Consejo, de 15 de julio de 1980, relativa a la aproximación de las legislaciones de los Estados Miembros sobre explotación y comercialización de aguas minerales naturales (Modificada por la Directiva 96/70/CEE del Parlamento Europeo y del Consejo, de 28 de octubre de $1996^{16}$ ). El objeto es definir, a efectos legales, lo que se entiende por aguas de bebida envasadas y fijar, con carácter obligatorio, las normas de manipulación y/o elaboración, circulación y comercialización.

Las aguas que se comercializan envasadas se clasifican en cuatro grupos: 1) Aguas minerales naturales: Las bacteriológicamente sanas que tengan su origen en un estrato o yacimiento subterráneo y que broten de un manantial en uno o varios puntos de alumbramiento, naturales perforados; 2) Aguas de manantial: Las potables de origen subterráneo que emergen espontáneamente en la superficie de la tierra o se captan mediante labores practicadas al efecto, con las características naturales de pureza que permiten su consumo, previa aplicación de los mínimos tratamientos físicos requeridos para la separación

\footnotetext{
${ }^{16}$ DOCE No L 229 de 30 de agosto de 1980 y DOCE No 299 de 23 de noviembre de 1996, respectivamente.
} 
de los elementos materiales inestables; 3) Aguas preparadas: Son las sometidas a los tratamientos autorizados físico-químicos necesarios para que reúnan las características establecidas en el Anexo I (Una serie de especificaciones microbiológicas y parasitológicas); 4) Aguas de consumo público envasadas: Aquellas aguas potables de consumo público, envasadas coyunturalmente para distribución domiciliaria con el único objeto de suplir las ausencias o insuficiencias accidentales de las aguas de consumo público distribuidas por la red general.

b.- Clasificación científico-técnica.- En función de la composición química de las aguas pueden realizarse diversas clasificaciones. Como modelo, adoptamos la que realiza la Sociedad Española de Hidrología Médica ${ }^{17}$ en base al contenido aniónico/catónico predominante. Los principales grupos de aguas minero-medinales son los siguientes:

- Aguas Cloruraradas.

- Aguas Sulfatadas.

- Aguas Sulfuradas.

- Aguas Bicarbonatadas.

- Aguas carbogaseosas.

- Aguas radiactivas.

- Aguas oligometálicas o de débil mineralización.

- Aguas ferruginosas.

Mención especial merecen los “peloides”, que es la denominación científica de los llamados vulgarmente lodos, fangos, barros, etc. El peloide termal es la mezcla obligatoria de un agua mineromedicinal con un producto sólido natural que precisa de un proceso preparatorio, y es utilizado en establecimientos balnearios. Existen diferentes tipos de peloides termales (fangos o lodos, turbas, biogleas y sapropelis) pero habitualmente, los más utilizados son los lodos.

Los fangos o lodos termales son la mezcla de un sólido mineral y un agua mineromedicinal clorurada o sulfurada. Los fangos se obtienen de los cauces de corrientes diversas, principalmente de los ríos. El componente sólido suele estar formado por cuarzos, calizas y arcillas, pudiendo considerarse como factores destacables los compuestos de silicio, aluminio, calcio, sulfatos, carbonatos y fosfatos. También tienen un cierto contenido orgánico formado por humus.

Según las características de cada peloide, se someten a procesos de impregnación, maceración o maduración para alcanzar la mayor homogeneidad y plasticidad. Las principales indicaciones terapéuticas son los reumatismos crónicos, las rigideces articulares y determinadas neuralgias.

El Decreto 55/1997, de 11 de julio, por el que se regulan las condiciones sanitarias de Balnearios, Baños Termales y Establecimientos de Talasoterapia y de aplicación de Peloides en la región de Murcia define los peloides como "aquellos productos formados por la mezcla de un agua mineral (incluyendo la de mar o lago salado) con un componente sólido resultante de procesos biológicos o geológicos, que, en estado natural o previa preparación adecuada, se utiliza tópicamente como agentes terapéuticos o con fines estéticos”.

\footnotetext{
${ }^{17}$ Sobre este apartado, se puede ampliar información en la página de internet (www.hidromed.com).
} 
c.- La talasoterapia.- El término “talhassa” proviene del griego y significa mar. La talasoterapia engloba todos los tratamientos en los que el mar interviene, desde la cura marina hasta la fisiobalneoterapia más moderna. Se trata de una técnica hidrológica que emplea el agua del mar y el clima marítimo con fines terapéuticos, aunque a veces, va asociada a otras técnicas como la masoterapia y fisioterapia.

El Decreto murciano citado anteriormente, define a los establecimientos de talasoterapia como "aquellos centros sanitarios que utilizan las aguas del mar o lago salado con fines terapéuticos o preventivos”.

Entre las principales acciones sobre el organismo de la talasoterapia, destaca el efecto tonificante y estimulante sobre el sistema nervioso de los baños de mar fríos (de 22 a $26^{\circ} \mathrm{C}$ ), que mejoran el equilibrio neurovegetativo y las funciones endocrinas, produciendo una sensación de bienestar. Cuando se aplica de forma hipertermal (entre 36 y 39²) produce un efecto sedante y analgésico ${ }^{18}$.

La talasoterapia forma parte de la oferta de especialidades de los curhoteles, y su aplicación, al igual que en las estaciones termales, se realiza por técnicas muy modernas y para todos los gustos. Como ejemplos, se pueden citar los servicios que ofrecen el Centro de Talasoterapia del Hotel Meliá Costa del Sol (Torremolinos) y el Centro Louison Bobet en el Hotel Byblos (Málaga): aquagym (gimnasia reeducativa), piscina analítica, baño burbujeante, ducha jet, ducha submarina, algoterapia (aplicación de algas), cavito sonic (onda ultrasonora en agua marina), presoterapia (drenaje linfático mecánico), etc.

\section{IV.- PROCEDIMIENTO PARA LA OBTENCIÓN DE LA DECLARACIÓN DE LAS AGUAS MINERALES O TERMALES}

La declaración de la condición de mineral de unas aguas determinadas será requisito previo para la autorización o concesión administrativa de su aprovechamiento como tales (Art. 24 LM y 39 RGRM). La declaración, que puede ser de oficio o a instancia de parte, es competencia de la Consejería de Industria de la Comunidad Autónoma, quien ha de oír a la de Sanidad y al Ministerio de Medio Ambiente, a los efectos de su exclusión del ámbito de la Ley de Aguas, si procediere (Art. 1.4 Reglamento del Dominio Público Hidráulico, aprobado por R.D. 849/1986).

En cuanto al procedimiento para su declaración, las legislaciones Autonómicas, salvo la de Cantabria ${ }^{19}$, se remiten de forma expresa a la legislación sobre minas. Para su iniciación se deberá presentar una solicitud ante la Consejería competente en materia de industria. El acto de iniciación del expediente se publicará en el Boletín de la Comunidad Autónoma ${ }^{20}$, haciendo constar si el expediente ha sido iniciado de oficio o a instancia de parte, y con expresión de la situación, características del acuífero o manantial y cuantos datos se

\footnotetext{
${ }^{18}$ Vid. SAN JOSÉ ARANGO, C. “Balnearios y Curhoteles andaluces”. Junta de Andalucía, 1996.

${ }^{19}$ Recuérdese que el Reglamento de desarrollo fue anulado por STS de 26 de noviembre de 1998.

${ }^{20} \mathrm{El}$ RM establece que se publicará en el BOE y BOP; Castilla-La Mancha, en BOE y en el Boletín Oficial de la Comunidad.
} 
consideren necesarios para su exacta determinación. Si el expediente se inicia a instancia de parte, deberán publicarse, asimismo, los datos personales del solicitante.

La solicitud deberá ir acompañada de un estudio hidrogeológico, que acredite suficientemente la procedencia de las aguas y la protección del acuífero frente a la contaminación, de acuerdo con las especificaciones establecidas en el Anexo II del R.D. 1164/1991, de 22 de julio, por el que se aprueba la Reglamentación Técnico Sanitaria.

La iniciación del expediente deberá notificarse, además, al propietario de las aguas alumbradas o manantial por cualquiera de las formas previstas en la Ley de Procedimiento Administrativo, a fin de que pueda personarse en el expediente en el plazo que se determine.

El siguiente trámite consiste en la realización de la toma de muestras. A estos efectos, la Consejería notificará a las partes interesadas el día y hora en que se procederá a la toma de las muestras de agua, girando visita al lugar de emplazamiento del alumbramiento con cargo al peticionario. La muestra se dividirá en tres partes que serán lacradas y selladas, entregándose una de ellas al solicitante; otra se depositará en la sede de la Delegación Provincial y otra se enviará al Instituto Tecnológico Geominero de España para su análisis correspondiente $^{21}$. En el supuesto de que el propietario del terreno se personase en la toma de muestras, ésta se dividirá en cuatro partes, entregándose una de ellas al mismo.

Por otra parte, también es preceptivo un informe de la Consejería competente en materia de sanidad que, en el caso de las aguas minero-medicinales, además será vinculante. En cualquier caso, en dichos análisis deberá determinarse si las aguas de que se trate cumplen las especificaciones previstas en el Anexo II del R.D. 1164/1991. Las propiedades salutíferas deberán apreciarse desde cuatro puntos de vista: a) Geológico e hidrológico; b) Físico, químico y físico-químico; c) Microbiológico; d) Farmacológico, fisiológico y clínico, en su caso).

A la vista de las actuaciones realizadas y de los informes recabados, la delegación provincial correspondiente emitirá su informe y elevará propuesta de resolución al Consejero competente en materia de industria. La resolución del expediente se notificará a los interesados y se publicará en el Boletín Oficial de la Comunidad Autónoma y en el Boletín Oficial del Estado ${ }^{22}$. También se publicará la pérdida de la condición de mineromedicinal.

Toda declaración de la condición de mineromedicinal o termal de las aguas será inscrita, de oficio, en el Registro de Aguas Minerales, Termales y de Manantial de la Consejería competente en materia de industria.

Y para finalizar este punto, un apunte histórico. Una buena parte de los balnearios existentes obtuvieron para sus aguas la declaración de "utilidad pública” hace muchos años, incluso con anterioridad al Real Decreto Ley 25 de abril de 1928 por el que se aprobó el Estatuo sobre la explotación de manantiales de aguas minero-medicinales (Cestona en 1782, Baños de Molgas en 1873, Arnedillo en 1887, Baños de la Concepción en 1843, Corconte en 1883, Mondariz en 1873, Montanejos en 1863, Palacio de Las Salinas en 1893, Alicún de las

\footnotetext{
${ }^{21}$ En Galicia, coincidiendo con la Reglamento General de la Minería, la toma de muestras, en los casos de aguas termales, se sustituirá por la toma de tres temperaturas espaciadas entre sí cuando menos dos horas.

${ }^{22}$ El Decreto 400/1996, de Galicia, sólo exige la publicación en el Diario Oficial de Galicia.
} 
Torres en 1870, etc.). Esta declaración facultaba al titular a gozar en concepto de dueño de los beneficios de la expropiación forzosa sobre los terrenos necesarios para su explotación; téngase en cuenta, la naturaleza privada de este tipo de aguas en la Ley de Aguas de 1879.

\section{V.- OTORGAMIENTO DE LA AUTORIZACIÓN O CONCESIÓN ADMINISTRATIVA DE APROVECHAMIENTO, SEGÚN LOS CASOS.}

Una vez declarada la condición de mineral de unas aguas, quien haya iniciado o se haya subrogado en el expediente, tendrá un plazo de seis meses en Castilla-La Mancha, y de un año en el resto de $\mathrm{CCAA}^{23}$, desde la notificación de la Resolución que así lo acuerde, para solicitar la concesión administrativa de aprovechamiento ${ }^{24}$. Cuando las aguas mineromedicinales o termales, objeto de aprovechamiento se encuentren en terreno de dominio público, éste se otorgará mediante concesión administrativa.

De acuerdo con la LM (que en su Disposición Final Quinta, deroga expresamente los Títulos I y III y el artículo 77 del R.D.L. 743/1928 por el que se aprueba el Estatuto sobre explotación de manantiales de aguas minero-medicinales) la autorización o concesión de aprovechamiento de aguas minerales reconoce a su titular el derecho exclusivo a utilizarlas, pero si no lo ejerce en el plazo marcado, este derecho puede ser expropiado.

La Administración concede derecho preferente al aprovechamiento de las aguas minerales a quien fuera el propietario de las mismas en el momento de la declaración de su condición de mineral, quien podrá ejercitarlo directamente, o cederlo a terceras personas. Si la declaración de la condición de mineral se ha realizado de oficio, o no se solicita la concesión de aprovechamiento -cuando se ha declarado a instancia de parte- la Consejería de Industria podrá conceder el aprovechamiento de las mismas mediante concurso público.

La solicitud de aprovechamiento se presentará en la Delegación de la Consejería competente en materia de industria, acompañada de los siguientes documentos:

a).- Los que confirmen la capacidad para ser titulares de derechos mineros y capacidad legal suficiente.

b).- Proyecto General de Aprovechamiento, suscrito por un Ingeniero de Minas (Superior o Técnico, según cuantía del proyecto), que contendrá los apartados siguientes:

- Descripción y obras ejecutadas en la captación.

- Conducción de dichas aguas hasta las instalaciones de aprovechamiento.

- Sistema de vigilancia y controles en la captación y su entorno físico.

- Régimen de explotación del acuífero, caudal, temporadas de máximo aprovechamiento, etc.

- Descripción detallada de las instalaciones principales y accesorias.

- Presupuesto total de las inversiones a realizar y de las obras e instalaciones proyectadas.

- $\quad$ Planos donde se consigne lo anteriormente expuesto.

\footnotetext{
${ }^{23}$ Según lo dispuesto en el Reglamento gallego y en el Reglamento General para el Régimen de la Minería.

${ }^{24}$ Este régimen difiere del regulado en el artículo 27 del Estatuto de 1928, que establecía "Una vez declarado de pública utilidad, se entenderá autorizada la explotación del manantial”.
} 

viabilidad.

c).- Estudio económico de la financiación del presupuesto con las garantías sobre su

d).- Perímetro de protección. Se solicitará, un perímetro de protección tendente a la conservación del acuífero, con un estudio geológico e hidrogeológico que lo justifique racionalmente.

Este perímetro se definirá por coordenadas geográficas referidas al meridiano de Greenwich, y estará constituido por tres zonas, que limitarán las actividades que se pretenden llevar a cabo en las mismas: Zona de restricciones máximas (ZMA), zona de restricciones medias (ZME) y zona de restricciones mínimas (ZMI). El titular del aprovechamiento tiene derecho a impedir que se realicen en el perímetro de protección que le hubiere sido fijado trabajos o actividades que puedan perjudicar el normal disfrute de las mismas (Art. 28.1 LM).

Sobre el perímetro de protección se ha pronunciado el Tribunal Supremo (STS de 14 de enero de 1994), desestimando un recurso de apelación del Ayuntamiento de Arnedillo, contra STSJ de La Rioja que determinaba la superficie afectada por el perímetro de protección de un manantial. El Tribunal desestima el recurso ya que la realidad de la titularidad "a perpetuidad" de una explotación centenaria afamada, su venta por el Ayuntamiento, su declaración de utilidad pública ya en 1887 y el uso pacífico e indisputado durante más de un siglo, de las aguas mineromedicinales legitiman a la sociedad explotadora del Balneario para solicitar el señalamiento del perímetro recurrido. Añade la Sala que de acuerdo con el Decreto de 25 de agosto de 1928, una vez declarada la utilidad pública se entenderá autorizada la explotación del manantial.

En cuanto al plazo de vigencia de la concesión de aprovechamiento, existe coincidencia entre las leyes de Extremadura y Galicia, al señalar un plazo de 30 años, prorrogable como máximo por otros dos plazos iguales, con un máximo de 90 años. CastillaLa Mancha también recoge establece un plazo inicial de 30 años, y la posibilidad de prórroga, sin establecer cuantas; y Cantabria no se pronuncia sobre este aspecto.

En ningún caso las legislaciones autonómicas podrán contemplar menos derechos a los titulares de las autorizaciones de aprovechamiento que los que actualmente reconoce la legislación básica estatal, y en cuanto a posibles causas de caducidad que se establezcan en las CCAA y que no estuviesen contempladas expresamente en la legislación estatal sobre minas no podrán ser aplicadas a las autorizaciones otorgadas en su día con arreglo a esta legislación.

\section{VI.- AUTORIZACIÓN SANITARIA}

Los balnearios tienen la condición de centros sanitarios, y por ello las distintas disposiciones de las CCAA se remiten a la legislación sanitaria (arts. 5 y 7 de la Ley cántabra; art. 19 de la Ley castellano-manchega; art. 22 de la Ley gallega, etc.). Antes de proceder a su apertura, tendrán que solicitar autorización administrativa para tal fin. El expediente se tramitará ante la Consejería competente en materia de sanidad, y se ajustará a la normativa sobre centros sanitarios de las distintas CCAA $^{25}$.

\footnotetext{
${ }^{25}$ ANDALUCÍA: Decreto 16/1994, de 25 de enero, desarrollado en la Orden de 2 de marzo de 1994; ARAGÓN: Decreto 237/1994, de 28 de diciembre (modificado por el Decreto 107/1996, de 11 de junio); BALEARES: Decreto 166/1996, de 26 de julio; CANARIAS: Decreto 225/1997, de 18 de septiembre; CANTABRIA: Decreto
} 
Con anterioridad al inicio de la actividad o apertura al público de un centro, servicio o establecimiento se deberá obtener la autorización previa de funcionamiento. Con este fin, el órgano sanitario autonómico comprobará, mediante visita de inspección, que se cumplen todas las condiciones y requisitos establecidos en la autorización de creación, modificación o traslado.

La solicitud se presentará en la Delegación provincial de sanidad, acompañada de los siguientes documentos:

- Documento acreditativo de la personalidad jurídica del solicitante.

- Documento que acredite la propiedad y dependencia jurídica del centro.

- Proyecto técnico de ejecución de obras (memoria, planos, plazo de ejecución, etc.).

- Memoria de instalaciones, aparatos e instrumental.

- Memoria descriptiva de las necesidades a satisfacer, así como de la naturaleza del centro.

- Certificación de cumplimiento de toda la normativa sobre urbanismo, construcción, instalaciones y seguridad.

- Plantilla de personal prevista con especificación de categorías profesionales.

- Previsión de eliminación de barreras arquitectónicas.

Una vez concedida la autorización previa y ejecutado el proyecto, se solicitará la autorización de funcionamiento, que tendrá la vigencia que se establezca en los respectivos Decretos autonómicos.

Finalmente, la Administración Sanitaria inscribirá de oficio la autorización, modificación o cancelación de la autorización de funcionamiento en el Registro de Centros, Servicios y Establecimientos Sanitarios de la CCAA donde se ubique. Los datos registrados podrán ser objeto de publicaciones y estadísticas por parte de la CCAA.

Aparte de esta legislación sanitaria, las CCAA establecen una serie de requisitos mínimos sobre instalaciones y personal sanitario de los balnearios:

a).- Instalaciones: Los establecimientos balnearios dispondrán, al menos, de:

- Medios de diagnóstico apropiados, así como un lugar de consulta adecuado.

- Medios precisos para la utilización terapéutica de las aguas y demás medios físicos específicos.

- Medios complementarios para facilitar el tratamiento.

- Un botiquín de urgencia con los medios necesarios para atender los servicios que con este carácter se presenten.

b).- Personal sanitario: Los establecimientos de Cantabria y Extremadura, estarán dotados, como mínimo, en cuanto a personal sanitario se refiere, de:

- Un Director-Médico.

65/1992, de 7 de septiembre; CASTILLA Y LEÓN: Decreto 93/1999, de 29 de abril; LA RIOJA: Decreto 5/1992, de 6 de febrero; PAIS VASCO: Decreto 396/1994, de 11 de octubre; etc. 
- Un médico consultor, cuya especialidad concuerde con la actividad terapéutica principal del balneario.

- Personal de enfermería y auxiliar necesario para el normal desarrollo de las actividades terapéuticas.

Las funciones del Director-Médico son básicamente, la coordinación de todo el personal sanitario, confeccionar anualmente una memoria estadística sobre las actividades asistenciales del balneario, redactar el Reglamento de Régimen Interior del establecimiento y supervisar el estado técnico e higiénico de las instalaciones balneoterápicas.

En Extremadura, cuando la explotación del establecimiento balneario no supere la cifra de 3.000 bañistas/año, las funciones del Director médico podrán ser asumidas por un Médico especialista, cuya especialidad concuerde con la actividad terapéutica principal del balneario, con funciones de consultor.

El Decreto-Ley de 25 de abril de 1928, por el que se aprobó el Estatuto sobre la explotación de manantiales y aguas minero-medicinales distinguía, a efectos de asistencia médica en dos grupos: los que estaban en ese momento atendidos por médicos del Cuerpo de Baños, y los que no estaban servidos por el expresado cuerpo.

Por último, es necesario precisar que las CCAA no podrán intervenir en el nombramiento o en las condiciones exigibles a los médicos y restantes profesionales sanitarios que presten servicios en balnearios, a la vista de lo dispuesto en los artículos 35, 36 y 38 de la Constitución y 88 y 89 de la Ley General de Sanidad.

\section{VII.- AUTORIZACIÓN SOBRE ALOJAMIENTOS TURÍSTICOS}

Con la llegada de la democracia y la constitucionalización del denominado Estado de las Autonomías que establece nuestra Carta Magna, se inicia una nueva etapa de la ordenación del turismo en España. El Artículo 148.1.18 de la Constitución dispone que las Comunidades Autónomas podrán asumir competencias en materia de: "promoción y ordenación del turismo dentro de su ámbito territorial”; y a partir de este momento, todas las CCAA recogen esta competencia exclusiva en sus Estatutos de Autonomía ${ }^{26}$. La transferencia efectiva de medios humanos, materiales y financieros para el ejercicio de las funciones que venía desarrollando el Estado en materia de turismo se realizó con mucha celeridad.

La connotación turística de los balnearios se encuentra en la propia definición, que de la palabra "balneario" establece el Diccionario de la Real Academia Española: "Edificio con baños medicinales y en el cual suele darse hospedaje”. Además, todas las disposiciones autonómicas sobre balnearios contemplan la posibilidad de disponer de instalaciones hoteleras, y/o de ocio, que tengan por objeto la prestación de servicios distintos a los meramente terapéuticos, y se remite expresamente a la legislación turística en cuanto su

\footnotetext{
${ }^{26}$ Vid. Art. 10,36 de la L. O. 3/1979, de 18 de diciembre, por la que se aprueba el Estatuto de Autonomía del País Vasco; Art. 9.2 de la L.O. 4/1979, de 18 de diciembre por la que se aprueba el Estatuto de Autonomía de Cataluña; Art. 27.21 de la L.O. 1/1981, de 6 de abril, por la que se aprueba el Estatuto de Autonomía de Galicia; art. 31.12 de la L.O. 5/1982, de 1 de julio, por la que se aprueba el Estatuto de Autonomía de la Comunidad Valenciana; art. 29.14 de la L.O. 1/1982, de 10 de agosto, por la que se aprueba el Estatuto de Autonomía de Canarias; art. 13.17 de la L.O. 6/1981, de 30 de diciembre, por la que se aprueba el Estatuto de Autonomía de Andalucía; ... etc.
} 
regulación y procedimiento de autorización; por lo que estamos ante un nuevo procedimiento administrativo.

Por otro lado, algunas Leyes de Turismo, como las de Andalucía y de Canarias $^{27}$ recogen la figura del "balneario" como una modalidad más de alojamiento turístico, por lo que es previsible una futura regulación en estas CCAA.

Son empresas de alojamiento turístico aquéllas que se dedican a prestar hospedaje a las personas, con o sin otros servicios de carácter complementario, mediante precio y con ánimo de lucro, en establecimientos abiertos al público. El ejercicio de esta actividad sólo podrá desarrollarse previa autorización y/o clasificación en alguna de las modalidades de alojamiento contemplada por la normativa de las respectivas CCAA.

Doctrinalmente, los alojamientos turísticos se agrupan en dos modalidades. Por un lado, los alojamientos hoteleros que aglutinan figuras tan variadas como los hoteles, hostales, moteles, pensiones, etc., que a su vez, en función de su régimen de explotación, pueden autorizarse con otras denominaciones (hotel-apartamento, hotel-residencia); y por otro, los alojamientos extrahoteleros, que engloban a los apartamentos turísticos, bungalows, villas turísticas, ciudades de vacaciones, campamentos de turismo, y más recientemente, alojamientos rurales y alojamientos en régimen de aprovechamiento por turnos. Aunque en algunas tipologías de alojamientos rurales ${ }^{28}$ (Hotel-Rural, Hospedería, Castillos, Posada) se aproximan más a un alojamiento de tipo hotelero.

Los establecimientos hoteleros fueron reglamentados con bastante homogeneidad en la década de los ochenta por la mayor parte de las CCAA ${ }^{29}$, basándose en el R.D. 1634/1983, de 15 de junio. No obstante, varias CCAA contemplan la posibilidad de que las Administraciones Turísticas reconozcan "especialidades" en función de los servicios prestados, ubicación, etc. Este es el caso del Decreto 267/1999, de 30 de septiembre, de ordenación de los establecimientos hoteleros de Galicia -último Decreto sobre clasificación de alojamientos hoteleros publicado en España- que contempla dentro de sus especialidades ${ }^{30}$ la modalidad de "Hoteles balnearios", con una definición que se ajusta bastante a la realidad del turismo de salud (Se consideran establecimientos hoteleros balnearios los que oferten la utilización de aguas termales como servicios hídricos de relax o terapéuticos, o la prestación

\footnotetext{
${ }^{27}$ Vid. Ley 12/1999, de 15 de diciembre, del Turismo de Andalucía; Ley 7/1995, de 6 de abril, de turismo de Canarias (Modificada por Ley 7/1997, de 4 de julio y Ley 5/1999, de 15 de marzo).

${ }^{28}$ Vid. Decreto 62/1995, de 2 de junio sobre alojamientos rurales en Baleares; Decreto 18/1998, de 5 de marzo, de regulación y ordenación de los establecimientos rurales en Canarias; Decreto 84/1995, de 11 de mayo, de ordenación de alojamientos rurales en Castilla y León; Decreto 11/1994, de 24 de febrero, sobre ordenación de los alojamientos en posadas; etc.
}

${ }^{29}$ ANDALUCÍA: Decreto 110/1986, de 18 de junio; ARAGÓN: Decreto 153/1990, de 11 de diciembre; ASTURIAS: Decreto 11/1987, de 6 de febrero, modificado por Decreto 27/1990, de 8 de marzo; CANARIAS: Decreto 149/1986, de 9 de octubre; CATALUÑA: Decreto 176/1987, de 9 de abril; MADRID: Decreto 120/1985, de 5 de diciembre; COMUNIDAD VALENCIANA: Decreto 153/1993, de 17 de agosto; etc.

\footnotetext{
${ }^{30}$ Aparte de la clasificación del establecimiento (hoteles y pensiones) se puede obtener de la Administración Turística el reconocimiento de algunas de las especialidades siguientes: Hoteles apartamentos, moteles, hoteles balnearios, hoteles deportivos, hoteles clubs, hoteles familiares, hoteles de ciudad, hoteles en playa, hoteles de montaña, hoteles de naturaleza, hoteles gastronómicos, hoteles de temporada, hoteles paradores, hoteles pousadas, hoteles rústicos, hoteles monumentos y albergues turísticos.
} 
de servicios de talasoterapia, ya sea en el propio establecimiento o en otro próximo con que los tengan concertados).

En el caso de los apartamentos turísticos han legislado las CCAA en las que predomina la oferta de "sol y playa" (Andalucía, Asturias, Baleares, Canarias, Cataluña, Comunidad Valenciana y País Vasco), mientras que en resto se aplicará la Orden de 17 de enero de 1967, sobre ordenación de apartamentos, bungalows y otros alojamientos de carácter turístico (modificada por la Orden de 12 de febrero de 1972 y la de 14 de marzo de 1975) y el R.D. de 15 de octubre de 1982 sobre ordenación de apartamentos y viviendas vacacionales.

Para la puesta en marcha de cualquier alojamiento turístico, independientemente de la modalidad, grupo o categoría del establecimiento es necesario obtener una autorización de la Administración Turística de la CCAA donde se ubique. La autorización turística tiene un carácter reglado, y se concederá siempre que el solicitante cumpla con los requisitos establecidos en la normativa aplicable. Independientes de esta autorización son las licencias de apertura y de edificación -si se trata de nueva construcción- que se tramitan ante el Ayuntamiento.

Y por último, una vez obtenida la autorización turística, la propia Administración la inscribirá de oficio y gratuitamente en el Registro de Empresas y Actividades Turísticas de la Comunidad Autónoma, que tienen naturaleza administrativa y carácter público. Para cada empresa se abrirá un legajo y se inscribirán el alta, las variaciones y las bajas.

\section{BIBLIOGRAFÍA}

- ARMiJO VALENZUELA, M. “Cura balnearia, medio ambiente, turismo”. Estudios Turísticos, nº 84. Madrid, 1984.

- ARMIJO VALENZUELA, M. y SAN MARTÍN BACAICOA, J. “Curas balnearias y climáticas. Talasoterapia y Helioterapia”. Editorial Complutense.

- DE LA CUÉTARA, J.M. “El nuevo régimen de las aguas subterráneas en España”. Tecnos, Madrid, 1989.

- DEL SAZ CORDERO, S. “Aguas subterráneas, aguas públicas (El nuevo Derecho de aguas)”. Marcial Pons, Madrid, 1990.

- FERNÁNDEZ ESPINAR, L.C. “Derecho de minas en España”. Comares, Granada, 1997.

- GALLEGO ANABITARTE, A., MENÉNDEZ REXACH, A. y DÍAZ LEMA, J.M. “El Derecho de aguas en España”. MOPU, Madrid, 1986.

- GONZÁLEZ PÉREZ, TOLEDO JÁUDENES Y ARRIETA ÁLVAREZ “Comentarios a la Ley de Aguas”. Cívitas, Madrid, 1987.

- GUAITA “Derecho Administrativo. Aguas, montes, minas”. Cívitas, Madrid, $2^{a}$ edición, 1986.

- LEÓN GROS, J. (Coord.) “Jornadas sobre Derecho de Aguas”. Aranzadi e Ilustre Colegio de Abogados de Málaga, 1999.

- MARTÍN RETORTILLO, S. “Derecho de Aguas”. Cívitas, Madrid, 1997.

- MAS BADIA, M.D. “El nuevo régimen jurídico de las aguas”. Tirant lo Blanch, Valencia, 1993.

- MELGOSA ARCOS, F.J. (Coord.). “Estudios de Derecho y Gestión Ambiental” (2 tomos). Fundación Cultural Santa Teresa y Junta de Castilla y León. Ávila, 1999.

- MELGOSA ARCOS, F.J. (Coord). “Actas de las III Jornadas de Derecho y Turismo”. Fundación Cultural Santa Teresa, Ávila, 1999.

- PÉREZ PÉREZ, E. “La propiedad del agua”. Bosch, Barcelona, 1998.

- SAN JOSÉ ARANGO, C. “Balnearios y Curhoteles andaluces”. Turismo Andaluz, S.A. 1996.

- SAN PEDRO MARTÍNEZ, A. "Hacia la definición del producto turístico balneario. Propuestas para su promoción”. Actas de las V Jornadas de Geografía del Turismo. Universidad Rovira i Virgili, Tarragona, 1998.

- TORRES VILLARROEL, D. “Uso y provechos de los baños de Ledesma” (Edición preparada por Juan Francisco Blanco). Balneario de Ledesma, 1988.

- VILLAR EZCURRA, J.L. “Régimen jurídico de las aguas minero-medicinales”. Montecorvo, Madrid, 1980.

- VVAA “Estudios sobre el balneario de Solán de Cabras” (2 $2^{\mathrm{a}}$ Edición). Real Academia Española de Farmacia.

- VVAA “50 años del turismo español”. Centro de Estudios Ramón Areces, Madrid, 1999.

- VVAA “Ley de Aguas: análisis de la Jurisprudencia Constitucional”. MAP, Madrid, 1990.

- ZARAGOZA RUBIRA, J.R. “Centros de bienestar y Curhoteles”. Area de Radiología y Medicina Física de la Universidad de Sevilla. (Documento de 1990). 